\title{
EDITORIAL
}

\section{Obliterative bronchiolitis in haematopoietic stem cell transplantation: can it be treated?}

\author{
D.H. Bryant
}

$\triangle$ llogeneic and autologous haematopoietic stem cell (HSC) transplantation are now both established as principal forms of treatment for patients with acute or chronic leukaemia, aplastic anaemia and various immunodeficiency syndromes, as well as various nonhaematological malignancies and auto-immune disorders [1-3]. However, major limitations to the successful use of HSC transplantation include respiratory complications and graft versus host disease. Lung dysfunction occurs in up to $50 \%$ of subjects after HSC transplantation, and pulmonary complications are among the most common causes of morbidity and mortality after this procedure [4].

Obliterative bronchiolitis (OB) is the most common noninfectious respiratory complication after HSC transplantation [5, 6], and usually develops as a late complication (after the first 100 days) and at the same time as chronic graft versus host disease develops. The onset of $\mathrm{OB}$ is usually $6-12$ months posttransplant, with the clinical severity ranging from asymptomatic to fulminant and fatal. The lack of a precise definition and uniform diagnostic criteria has led to variations in the reported incidence, between 0 and $50 \%$, with commonly quoted figures being between 5 and $20 \%[7,8]$. Although OB has been described after autologous HSC transplantation [9], this is a rare complication, a fact usually attributed to the absence of chronic graft versus host disease after autologous HSC transplantation.

The most commonly identified risk factor for OB after HSC transplantation is chronic graft versus host disease, but other risk factors include human leukocyte antigen mismatch or use of an unrelated donor, use of busulfan or methotrexate, increased age, male sex, cigarette smoking and the presence of airflow limitation prior to transplantation $[6,8,10]$. The pathophysiology is incompletely understood, but, given its strong association with chronic graft versus host disease, it is believed that the disorder occurs as a result of an alloimmune process, with donor T-lymphocytes being the likely mediators of the response [11], which is characterised histopathologically by a predominantly lymphocytic bronchiolar and peribronchiolar inflammatory infiltrate, as well as concentric bronchiolar fibrosis [6]. This mechanism is supported by a murine model [12]. Similar long-term complications have been reported after lung transplantation, indicating that $\mathrm{OB}$ is a manifestation of lung rejection, as well as part of the chronic graft versus host

CORRESPONDENCE: D.H. Bryant, Dept of Thoracic Medicine, St Vincent's Hospital, 438 Victoria Street, Darlinghurst, NSW 2012, Australia. Fax: 61 283826772. E-mail: dbryant@stvincents.com.au syndrome that occurs after allogenic HSC transplantation. OB after HSC transplantation is an earlier and less common complication than in patients after lung transplantation [7]. However, a recent study in subjects after lung transplantation has provided a new insight into the natural history of $\mathrm{OB}$ in that clinical setting, and suggests that repetitive low-grade acute cellular rejection episodes have a cumulative effect on the airways, leading to clinically relevant alloimmunemediated airway injury, which results in the $\mathrm{OB}$ syndrome [13]. HopKINS et al. [13] also point out that other sources of nonalloimmune injury (such as gastro-oesophageal reflux and lower respiratory infection) may have an additive affect. In the light of the irreversible nature of established $\mathrm{OB}$, it is, therefore, hoped that controlling both alloimmune and nonalloimmune epithelial injury after transplantation may provide an opportunity for reducing pulmonary complications and improving survival [14].

A definitive diagnosis of $\mathrm{OB}$ is based on a histological examination of lung tissue, which, because of the patchy nature of the process, generally requires surgical lung biopsy. Transbronchial lung biopsies generally provide an insufficient sample and have an unacceptably high false-negative diagnostic rate $[6,8]$. However, a presumptive diagnosis can be made in the appropriate clinical setting. In a patient $>100$ days post-transplant, who develops breathlessness and bronchodilator nonresponsive airflow limitation, and who has moderateto-severe chronic graft versus host disease, with a clear chest radiograph and a high-resolution computed tomography scan showing thickened or dilated small airways with mosaic attenuation, the diagnosis of $\mathrm{OB}$ is highly probable [6].

The clinical course is variable, but the median mortality rate is in excess of $60 \%$, with most authorities agreeing that improvement in lung function occurs infrequently and that stabilisation, which occurs in no more than one third of subjects, is usually the best outcome that can be achieved $[15,16]$. In controlled clinical trials, no agents have been shown to be of proven efficacy in the management of OB after HSC transplantation. Current recommendations are derived from the opinions of experts in the field and from anecdotal reports. Treatment is usually directed at the exclusion and treatment of any secondary infection, the control of any asthmatic contribution and the augmenting of immunosuppression [16, 17]. Worsening of the patient's condition is likely to occur, particularly following lower respiratory tract infection, and, for this reason, the threshold for investigation and treatment in this group of subjects should be low. 
Therefore, prevention, early detection and effective treatment for OB after HSC transplantation remain prime objectives if patient outcomes are to be improved. Due to their association, improved measures to prevent and treat chronic graft versus host disease will undoubtedly be of major importance in helping to prevent OB. Although the use of cyclosporine has led to a reduction in the rates of chronic graft versus host disease, and of $\mathrm{OB}$, additional immunosuppression measures will need to be balanced against an increase in the rates of opportunistic infection.

There have been several recent studies in animal models looking at other agents that may be helpful in preventing the development of OB. These include inhibition of Janus kinase (JAK) 3, with a resulting effect on platelet-derived growth factor, the modulation of transforming growth factor (TGF)- $\beta_{1}$ and of agents influencing vascular endothelial growth factor all in rat transplant models [18, 19]. Studies in the murine model using pirfenidone, which also affects TGF- $\beta_{1}$, have demonstrated a delay in the onset, as well as a reduction in the severity, of OB when administered early in the post-transplant period, suggesting that pirfenidone may be a candidate drug to be evaluated in human subjects [20].

Of particular interest are recent studies of the use of azithromycin for patients with $\mathrm{OB}$ after transplantation procedures. A recent open-labelled study of eight human subjects after lung transplantation suggests that azithromycin, in a dosage of $250 \mathrm{mg} \cdot$ day $^{-1}$ for 5 days, followed by $250 \mathrm{mg}$ every other day, when added to the patient's pre-existing immunosuppressive therapy, results in a significant improvement in the degree of airway narrowing [21]. KURDOWSKA et al. [22] postulated that azithromycin may have produced this improvement by the inhibition of interleukin- 8 release by human alveolar macrophages [23] or by an increase in the apoptosis of neutrophils. In this issue of the European Respiratory Journal, KHALID et al. [24] have produced further evidence to suggest that there is a potential role for azithromycin in the treatment of $\mathrm{OB}$. Theirs is an observational study of eight patients out of 153 subjects undergoing allogeneic HSC transplantation. The eight patients with OB were given azithromycin $500 \mathrm{mg}$ daily for 3 days, then $250 \mathrm{mg}$ three times per week for 12 weeks. Clinically significant improvement was achieved in both forced expiratory volume in one second and forced vital capacity with the average improvement being $21 \%$. KHALID et al. [24] postulate that macrolide antibiotics may have a beneficial effect in patients with OB after HSC transplantation, by virtue of a range of antiinflammatory effects, not all of which are well understood.

In the light of the results of KHALID et al. [24], and in view of the poor prognosis of obliterative bronchiolitis in patients after haematopoietic stem cell transplantation, a larger scale randomised trial to assess the benefit of this form of treatment is needed. This study highlights the need for continued research in this important area and provides the exciting prospect of improved patient outcome for a complication that otherwise carries a grim prognosis. It goes without saying that a major challenge exists to understand more precisely the factors, both immune and nonimmune, which contribute to the development of obliterative bronchiolitis after haematopoietic stem cell transplantation. Although it is probable that each of these injuries is additive, current evidence indicates that the alloimmune injury is the critical insult, and that measures which offer the prospect of curtailing this injury, such as those reported in this Journal by KHALID et al. [24], offer the promise of improved survival for patients after haematopoietic stem cell transplantation.

\section{REFERENCES}

1 Milojkovic D, Mufti JG. Extending the role of allogenic stem cell transplantation. Lancet 2001; 357: 652-654.

2 Hensel M, Breitbart A, Ho AD. Autologous hematopoeitic stem-cell transplantation for Behcet's Disease with pulmonary involvement. N Engl J Med 2001; 344: 69.

3 Traynor AE, Schroder J, Rosa RM, et al. Treatment of severe systemic lupus erythematosus with high-dose chemotherapy and hematopoeitic stem-cell transplantation. Lancet 2000; 356: 701-707.

4 Chan CK, Hyland RH, Hutcheon MA. Pulmonary complications following bone marrow transplantation. Clin Chest Med 1990; 11: 323-332.

5 Quabeck K. The lung as a critical organ in marrow transplantation. Bone Marrow Transplant 1994; 14: Suppl. 4, S19-S28.

6 Bryant D. Pulmonary complications. In: Atkinson K, Champlin R, Ritz J, Fibbe WE, Ljungman P, Brenner MK, eds. Clinical bone marrow and blood stem cell transplantation. 3rd Edn. Cambridge, Cambridge University Press, 2004; pp. 1466.

7 Philit F, Wiesendanger T, Archimbaud E, et al. Post transplant obstructive lung disease ("bronchiolitis obliterans"): a clinical comparative study of bone marrow and lung transplant patients. Eur Respir J 1995; 8: 551-558.

8 Marras T, Chan C. Obliterative bronchiolitis complicating bone marrow transplantation. Semin Respir Crit Care Med 2003; 24: 531-541.

9 Paz HL, Crilley P, Patchefsky A, et al. Bronchiolitis obliterans after autologous bone marrow transplantation. Chest 1992; 101: 775-778.

10 Chan CK, Hyland RH, Hutcheon MA, et al. Small-airways disease in recipients of allogeneic bone marrow transplants. An analysis of 11 cases and a review of the literature. Medicine (Baltimore) 1987; 66: 327-340.

11 Ratanatharathorn V, Ayash L, Lazarus HM, et al. Chronic graft-versus-host disease: clinical manifestations and therapy. Bone Marrow Transplant 2001; 28: 121-129.

12 Cooke KR, Krenger W, Hill G, et al. Host reactive donor Tcells are associated with lung injury after experimental allogenic bone marrow transplantation. Blood 1998; 92: 2571-2580.

13 Hopkins PM, Aboyoun CL, Chhajed PN, et al. Association of minimal rejection in lung transplant recipients with obliterative bronchiolitis. Am J Respir Crit Care Med 2004; 170: 1022-1026.

14 Egan J. Obliterative bronchiolitis after lung transplantation. Am J Respir Crit Care Med 2004; 170: 931-932.

15 Chan CK. Bone marrow transplantation bronchiolitis obliterans. In: Epler G, ed. Diseases of the bronchioles. New York, Raven, 1994; pp. 247-257.

16 Afessa B, Litzow MR, Tefferi A. Bronchiolitis obliterans and other late onset non infectious pulmonary 
complications in hematopoietic stem cell transplantation. Bone Marrow Transplant 2001; 28: 425-431.

17 Crawford SW, Clark AG. Bronchiolitis associated with bone marrow transplantation. Clin Chest Med 1993; 14: 741-749.

18 Rousvoal G, Zhang S, Berry G, et al. JAK 3 inhibition with CP 690, 550 prevents obliterative bronchiolitis in a rat tracheal transplant model. Transplantation 2004; 78: Suppl. 1,46 .

19 Krebs R, Tikkanen JM, Nykanen AI, et al. Dual role of vascular endothelial growth factor in experimental obliterative bronchiolitis. Transplantation 2004; 78: Suppl. 1, 541.

20 McKane BW, Fernandes F, Narayanan K, et al. Pirfenidone inhibits obliterative airways disease in a murine heterotopic tracheal transplant model. Transplantation 2004; 77: 664-669.
21 Verleden GM, DuPont LJ. Azithromycin therapy for patients with bronchiolitis obliterans syndrome after lung transplantation. Transplantation 2004; 77: 1465-1467.

22 Kurdowska A, Noble JM, Griffith DE. The effects of azithromycin and clarithromycin on ex vivo interleukin-8 (IL-8) release from whole blood and IL-8 production by human alveolar macrophages. J Antimicrob Chemother 2001; 47: 867-870.

23 Koch CC, Esteban DJ, Chin AC, et al. Apoptosis, oxidative metabolism and interleuken-8 production in human neutrophils exposed to azithromycin: effects of Streptoccus pneumoniae. J Antimicrob Chemother 2000; 46: 19-26.

24 Khalid M, Al Saghir A, Saleemi S, et al. Azithromycin in bronchiolitis obliterans complicating bone marrow transplantation: a preliminary study. Eur Respir J 2005; 25: 490-493. 